\title{
Efficacy of Nonprescription Moisturizers for Atopic Dermatitis: An Updated Review of Clinical Evidence
}

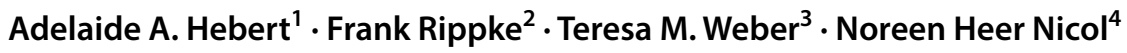

Published online: 10 June 2020

(c) The Author(s) 2020

\begin{abstract}
Twice-daily moisturization is recommended by international guidelines as the bedrock of the management of atopic dermatitis (AD). Moisturizers should be selected based on proven clinical effectiveness in improving the skin barrier and improving the symptoms of $\mathrm{AD}$. We searched the PubMed database for clinical trials assessing daily moisturization for the treatment of AD published between 2006 and 2019. Studies had to assess the efficacy of commercially available moisturizers using objective measures of corneometry, transepidermal water loss, or incidence of flare as endpoints, and treatments had to be currently available to patients. Clinical studies showed that moisturization (typically twice daily) significantly improved the skin barrier in adults and children with AD. Longer-term flare studies showed that daily moisturization reduced the incidence of flares and extended the time between flares. Proactive moisturization of infants at high risk of developing AD may reduce its manifestation. Therapeutic moisturizers for $\mathrm{AD}$ are specifically formulated with ingredients that target symptoms of AD, such as itch, inflammation, or compromised skin barrier. The US FDA requires that any moisturizer available in the USA and claiming to treat $\mathrm{AD}$ must contain colloidal oatmeal. Healthcare providers can maximize compliance and outcomes by educating patients on the benefits of liberally applying a therapeutic moisturizer twice daily to support the skin barrier and help reduce the incidence of flares. Specific recommendations should be for clinically tested moisturizers evaluated using objective, validated skin assessments.
\end{abstract}

\section{Introduction}

Atopic dermatitis (AD) affects more than 18 million people in the USA [1]. Daily moisturization is the standard or "bedrock" of the basic disease management of $\mathrm{AD}[2,3]$. A comprehensive review of 14 independent published guidelines from across the globe (USA, UK, Europe, Japan, Korea, Singapore, Canada, South Africa, and individual European countries) revealed that daily moisturization was a consistent recommendation for $\mathrm{AD}$ management [4].

Adelaide A. Hebert

Adelaide.A.Hebert@uth.tmc.edu

1 Department of Dermatology, University of Texas McGovern Medical School, 6655 Travis, Suite 980, Houston, TX 77030, USA

2 Research and Development, Beiersdorf, Hamburg, Germany

3 Research and Development, Beiersdorf Inc., Wilton, CT, USA

4 College of Nursing, University of Colorado, Anschutz Medical Campus, Aurora, CO, USA

\section{Key Points}

Daily moisturization is the bedrock of atopic dermatitis (AD) management, as recommended by all international guidelines.

Therapeutic moisturizers developed specifically for the treatment of $\mathrm{AD}$ demonstrate improved skin barrier and reduced incidence of flares in clinical trials.

Healthcare providers can help improve the skin condition of patients by informed recommendation of clinically proven, scientifically validated therapeutic nonprescription moisturizers and encouragement to use the product regularly.

Guidelines recommend liberal application of moisturizer on lesional and nonlesional skin, ideally at least twice daily $[4,5]$. In mild $\mathrm{AD}$, a daily moisturizer may be the primary therapy but should also be continued as complementary 
therapy when treating moderate and severe disease $[2,3]$. Reviews of this subject area have revealed similar recommendations [6-9]; however, these studies were mainly focused on the active ingredients applied or on less recent or selected studies, respectively.

The objective of this review was to evaluate and present the clinical data behind commercially available products in a succinct guide based on accepted scientific criteria, so that healthcare providers can make informed choices and recommendations to their patients for proven therapies.

\section{Clinical Evidence That Moisturizers Can Improve Outcomes in Atopic Dermatitis (AD)}

$\mathrm{AD}$ is characterized by compromised epidermal barrier integrity. Even the skin of a patient that is not flaring is compromised and has imperfect barrier function [10-14]. The purpose of daily moisturization is to repair and support the skin barrier, thereby reducing the risk of flares.

To evaluate the clinical efficacy of daily emollient therapy for improving the skin barrier of patients with $\mathrm{AD}$, we conducted a review of clinical studies of moisturizers in $A D$ treatment. We searched the PubMed database using the terms "atopic dermatitis" OR "atopic" OR "eczema" plus all combinations of "barrier," "topical," "steroid-free," "moisturizer," and "moisturization." Reference lists were also reviewed, particularly those from a 2017 Cochrane database review [15] and a 2018 evidence-based review [9].

Clinical studies were selected to provide practicing dermatologists with relevant data on commercially available, clinically tested nonprescription moisturizers to enable them to make informed recommendations. Clinical trials were selected that included study subjects with a diagnosis of $\mathrm{AD}$ or who were at high risk for developing AD. Studies had to include objective, biophysical barrier measures of transepidermal water loss (TEWL) and/or corneometry (see Table 1) to assess their efficacy at improving the skin barrier. If validated clinical assessment scales were included in these studies, these results were also reviewed. In addition, we selected studies that examined the ability of daily moisturization to prevent disease onset (primary prevention) or $\mathrm{AD}$ flares (secondary prevention).

Studies that only assessed clinical symptoms or measured moisturization at $24 \mathrm{~h}$ after a single application were excluded, as were studies reporting on medical devices, products requiring a prescription (e.g., Atopiclair, EpiCeram), and studies testing single ingredients such as glycerol [16]. Studies were limited to those published from January 2006 until December 2019 that tested products that are currently on the market.

\section{Summary of Clinical Study Findings}

The literature search identified 13 different nonprescription and cosmetic products tested in pediatric populations and 11 tested in adult populations with AD. Overall, clinical studies demonstrated that daily moisturization increased skin hydration and decreased TEWL in both children and adults (Table 2). While the majority of studies tested twice-daily application, once-daily treatment also showed skin barrier improvements. The analyses were mostly comparisons with baseline values, demonstrating improvements over time. Side-by-side comparisons (splitbody) of treatment versus no treatment also indicated that, in almost all cases, moisturization improved skin barrier integrity compared with no treatment.

Table 1 Validated skin assessments commonly used in atopic dermatitis studies

\begin{tabular}{|c|c|c|c|}
\hline Assessment & Assessment type & Description & Outcome \\
\hline TEWL & Biophysical & $\begin{array}{l}\text { Tewa Meter or similar device directly measures water } \\
\text { loss from skin in } \mathrm{g} / \mathrm{m}^{2} / \mathrm{h}\end{array}$ & $\begin{array}{l}\text { High values indicate defective barrier function; low } \\
\text { values indicate tight barrier }\end{array}$ \\
\hline Corneometry & Biophysical & $\begin{array}{l}\text { Corneometer indirectly measures hydration by detecting } \\
\text { capacitance changes due to water content in skin }\end{array}$ & $\begin{array}{l}\text { High values indicate greater hydration; low values } \\
\text { indicate dry skin }\end{array}$ \\
\hline SCORAD & Clinical & Measure of signs ${ }^{\mathrm{a}}$ and symptoms ${ }^{\mathrm{b}}$ on scale of $0-103$ & High score indicates more severe clinical phenotype \\
\hline EASI & Clinical & Measure of signs ${ }^{c}$ on scale of $0-72$ & High score indicates more severe clinical phenotype \\
\hline ADSI & Clinical & Measure of signs and symptoms ${ }^{\mathrm{d}}$ on scale of $0-15$ & High score indicates more severe clinical phenotype \\
\hline
\end{tabular}

ADSI Atopic Dermatitis Severity Index, EASI Eczema Area and Severity Index, SCORAD Scoring Atopic Dermatitis, TEWL transepidermal water loss

${ }^{a}$ Redness, swelling, oozing/crusting, excoriation, lichenification, dryness

${ }^{\mathrm{b}}$ Itching, sleeplessness

${ }^{\mathrm{c}}$ Erythema, edema/papulation, excoriation, lichenification

${ }^{\mathrm{d}}$ Erythema, pruritus, exudation, excoriation, lichenification 
Flare studies indicated that daily moisturization significantly reduced the number of flares compared with untreated skin. A pooled analysis of six of the studies $(n=607)$ included in the Cochrane study, looking specifically at prevention of flares, demonstrated that daily moisturization significantly reduced the number of flares compared with untreated controls $(p<0.0006)$ [15].

Two studies investigated the ability of daily moisturization to proactively prevent flares in patients with AD. These randomized, 6-month studies investigating the effect of twice-daily moisturizer compared with no treatment demonstrated that both the US Eucerin Eczema Relief Body Cream and the Swedish Canoderm Cream significantly lengthened time to flare and reduced the total number of flares, in pediatric and adult populations, respectively $[44,39]$. The median time to flare was $>180$ days with daily moisturizer treatment in both studies, versus 28 and 30 days in the untreated groups of the pediatric and adult studies, respectively [44, 39]. Pooled analyses of these studies indicated that daily moisturization significantly reduced the risk of flare $(p=0.001)$ and the rate of flare by a factor of $3.74(p=0.0002)$ compared with untreated controls [15].

In addition to preventing flares in patients diagnosed with $\mathrm{AD}$, proactive treatment of high-risk neonates reduced the development of $\mathrm{AD}$ [37]. This study was predicated on the knowledge that a family history of $\mathrm{AD}$, allergic rhinitis, or asthma increases the likelihood of an infant developing AD. In this study, 124 neonates with a first-degree relative with one of these conditions were randomized to receive full body coverage (scalp excluded) of an emollient (Aquaphor Healing Ointment, 50\% paraffin in white petrolatum, Cetaphil Cream, Doublebase Gel, or sunflower oil) daily, starting at or before 3 weeks of age. At 6 months, only $22 \%$ of neonates receiving daily emollient therapy developed AD versus $43 \%$ in the control group, corresponding to a significant risk reduction of $50 \%$ [37]. Several studies of proactive moisturization of highrisk infants support the effectiveness of primary prevention of AD [47], although another study by the original investigators showed a protective but nonsignificant effect of daily use of a therapeutic moisturizer (AD diagnosed in only 13.2 vs. $25.0 \%$ in the control group at 12 months), likely because the study was underpowered [42].

Many of the studies reviewed were not randomized controlled trials (RCTs). Large-scale RCTs are the gold standard for pharmaceutical approvals, but the high costs associated with these trials are impractical when testing nonprescription product formulations that will not be covered by insurance but need to be available to consumers at a reasonable cost.

Moreover, topical nonprescription formulations have multiple components that contribute to their efficacy, rendering "placebo-controlled" studies impossible. Consequently, most "controls" are an untreated group or an untreated side of a patient in the case of split-body studies. Although rare, a few vehicle-controlled studies exist $[36,43]$ that eliminate multiple key "active" ingredients and compare outcomes with the complete formulation.

Currently, there is no gold standard for nonprescription product testing. The endpoints chosen in this literature search-TEWL, corneometry, symptom relief-appear to be robust measures. Time to flare and number of flares versus untreated controls could also be considered objective and relevant measures. However, study design details such as sample size, length of study, controls, and blinding were not standardized. Moreover, pruritus is among the primary symptoms of $\mathrm{AD}$, yet assessment measures for pruritus are not standardized and are frequently omitted from study designs.

\section{Types of Moisturizers}

Moisturizers come in many formulations, ranging from oils and ointments to lotions and gels. Moisturizers are not created with equal component ingredients; some can actually worsen skin function and even induce skin irritation [48, 49]. Traditionally, ointments and occlusives were thought to be the most beneficial for eczema because of their protective effects, whereas creams were assumed to provide better moisturization than lotions because of their greater viscosity. However, these premises are no longer true as modern technology has allowed the development of efficacious, more aesthetically pleasing formulations that improve compliance and therefore outcomes [50].

Moisturizers have evolved from providing basic barrier protection (occlusives) to hydrating care (humectant enriched) to products that address specific skin conditions (therapeutic).

Occlusives include ointments (mostly water-free lipid formulas) and basic water-in-oil creams and lotions (emulsions or suspensions of water into hydrophobic emollients and oils) that reduce TEWL and protect the skin against external irritants.

Humectant-enriched moisturizers include cream and lotion formulations of oil-in-water and water-in-oil emulsions as well as hydrogels. Incorporating humectant ingredients ranging from glycerin to natural moisturizing factor (NMF) components of the skin (e.g., urea, lactate, amino acids, pyrrolidone carboxylic acid, hyaluronic acid), these moisturizers hydrate the skin by attracting and binding water.

Therapeutic moisturizers are not restricted to any formulation type, as they are designed to address the specific symptoms of diseased skin. These formulations improve 


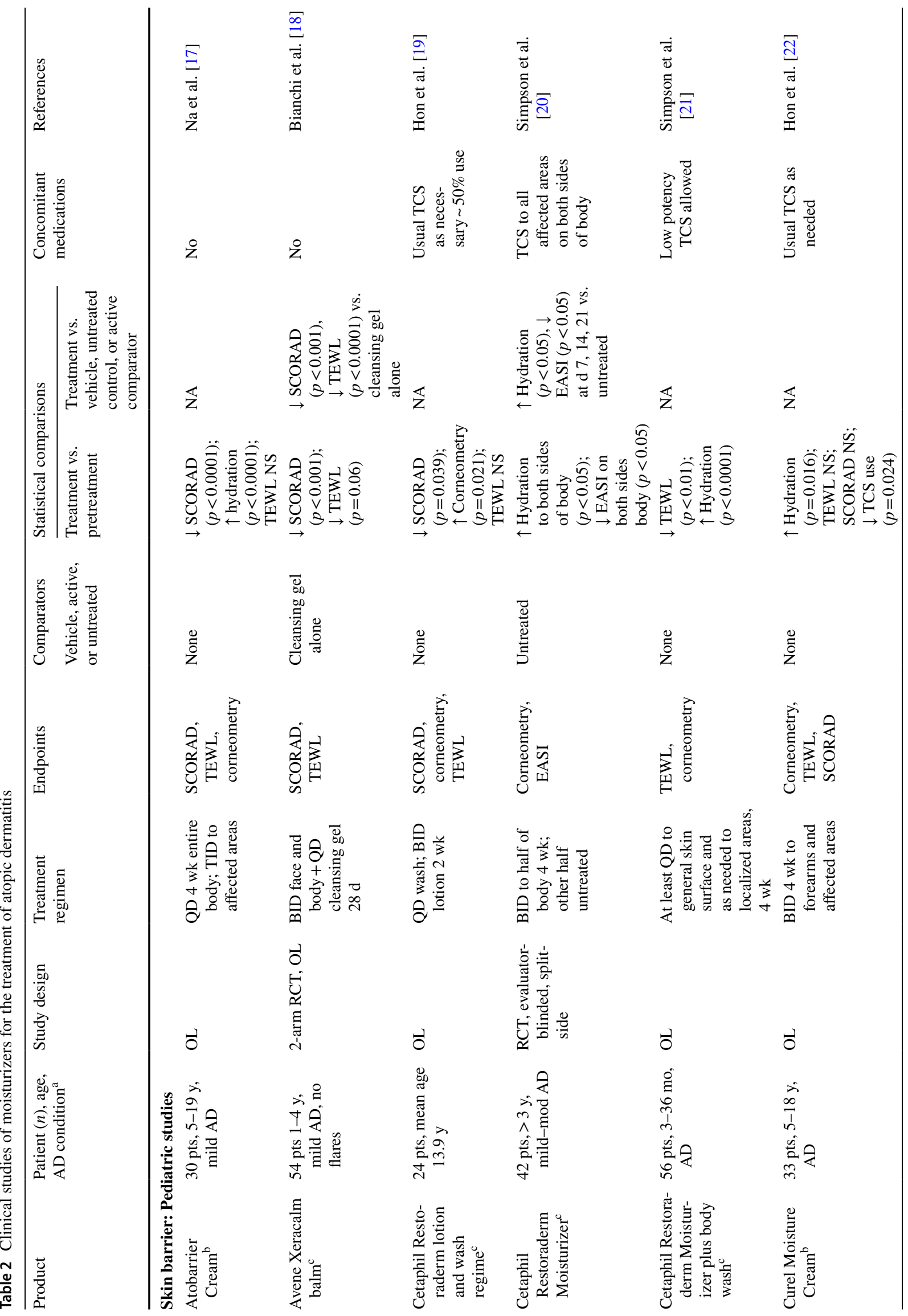




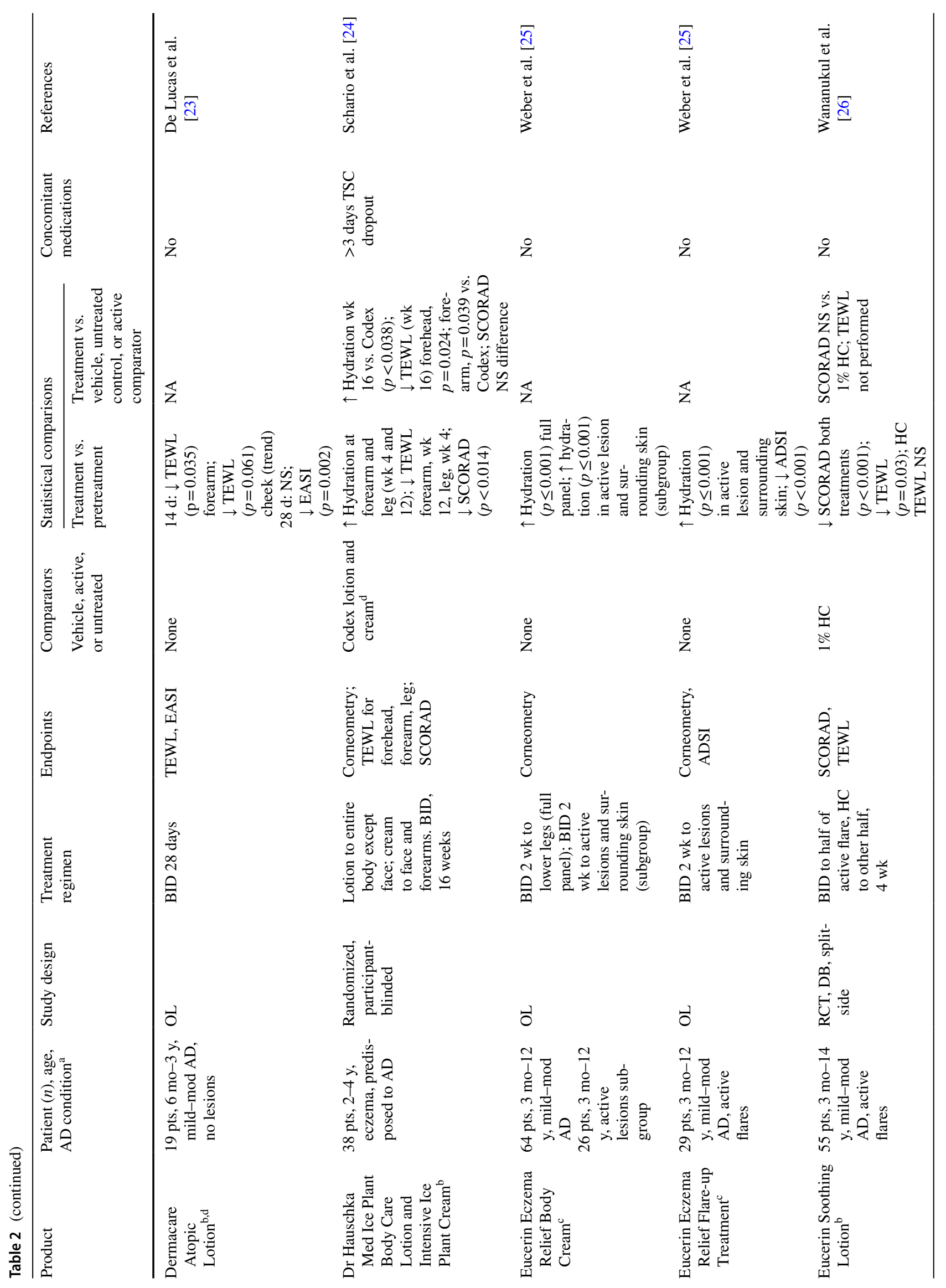




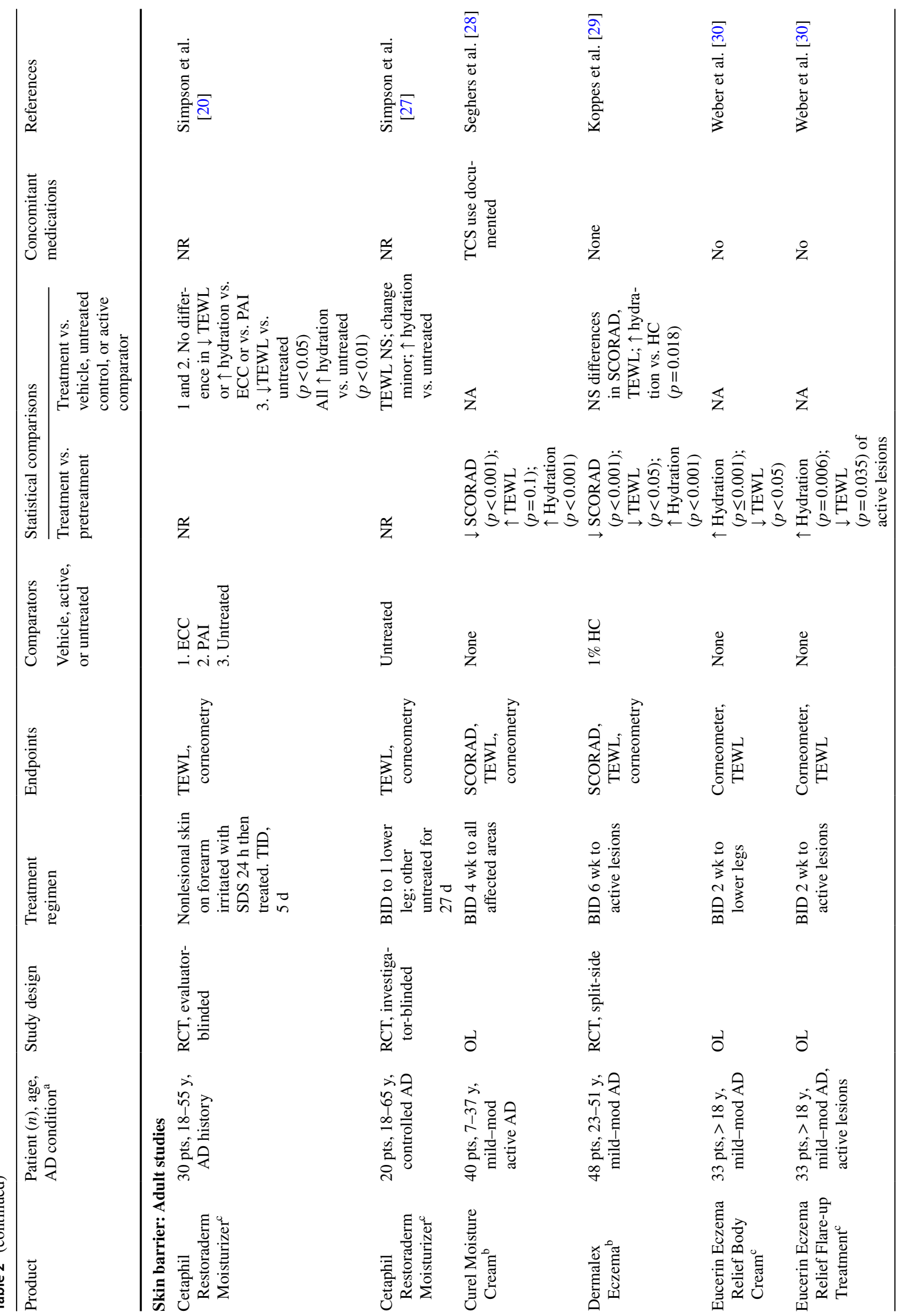




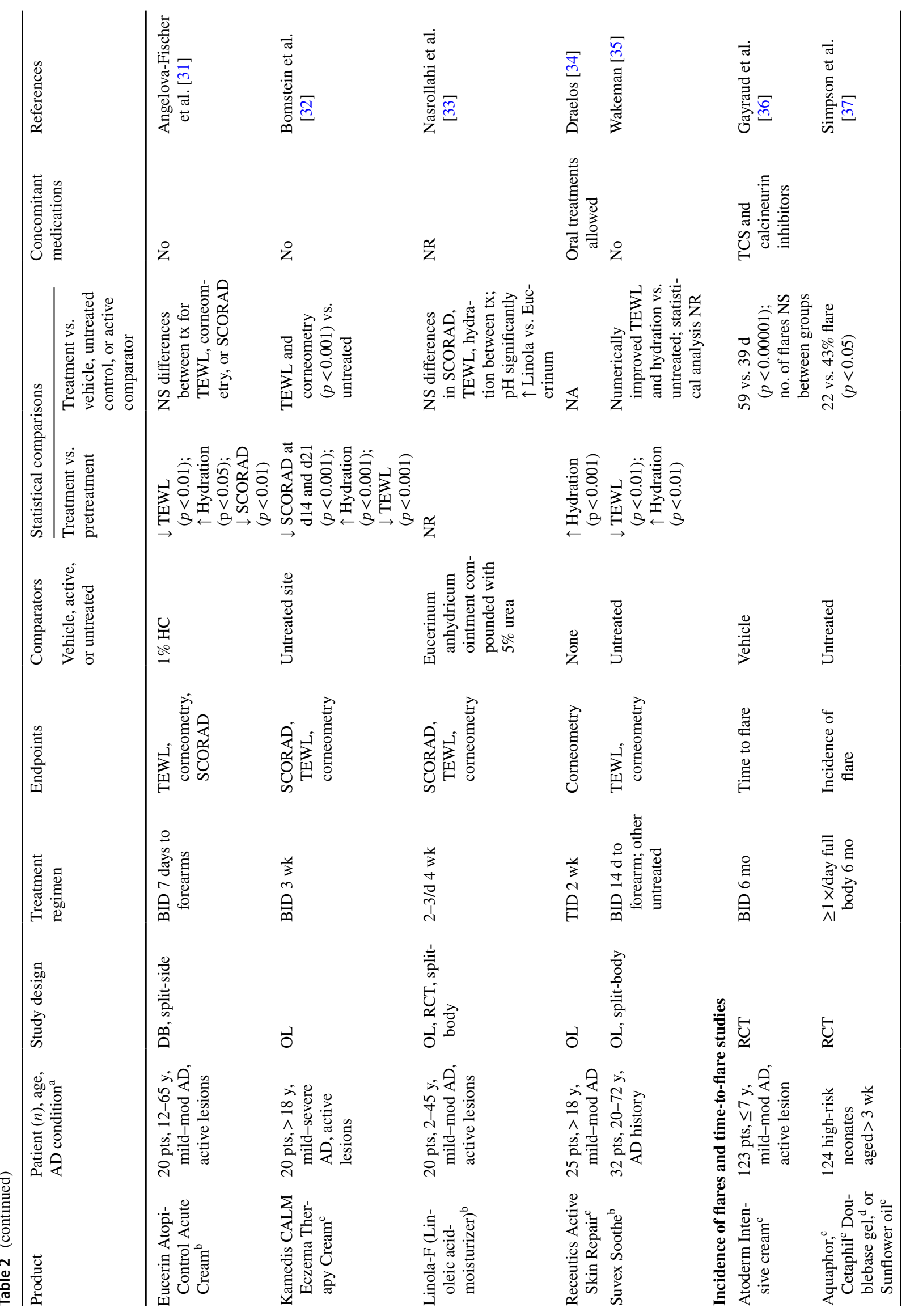




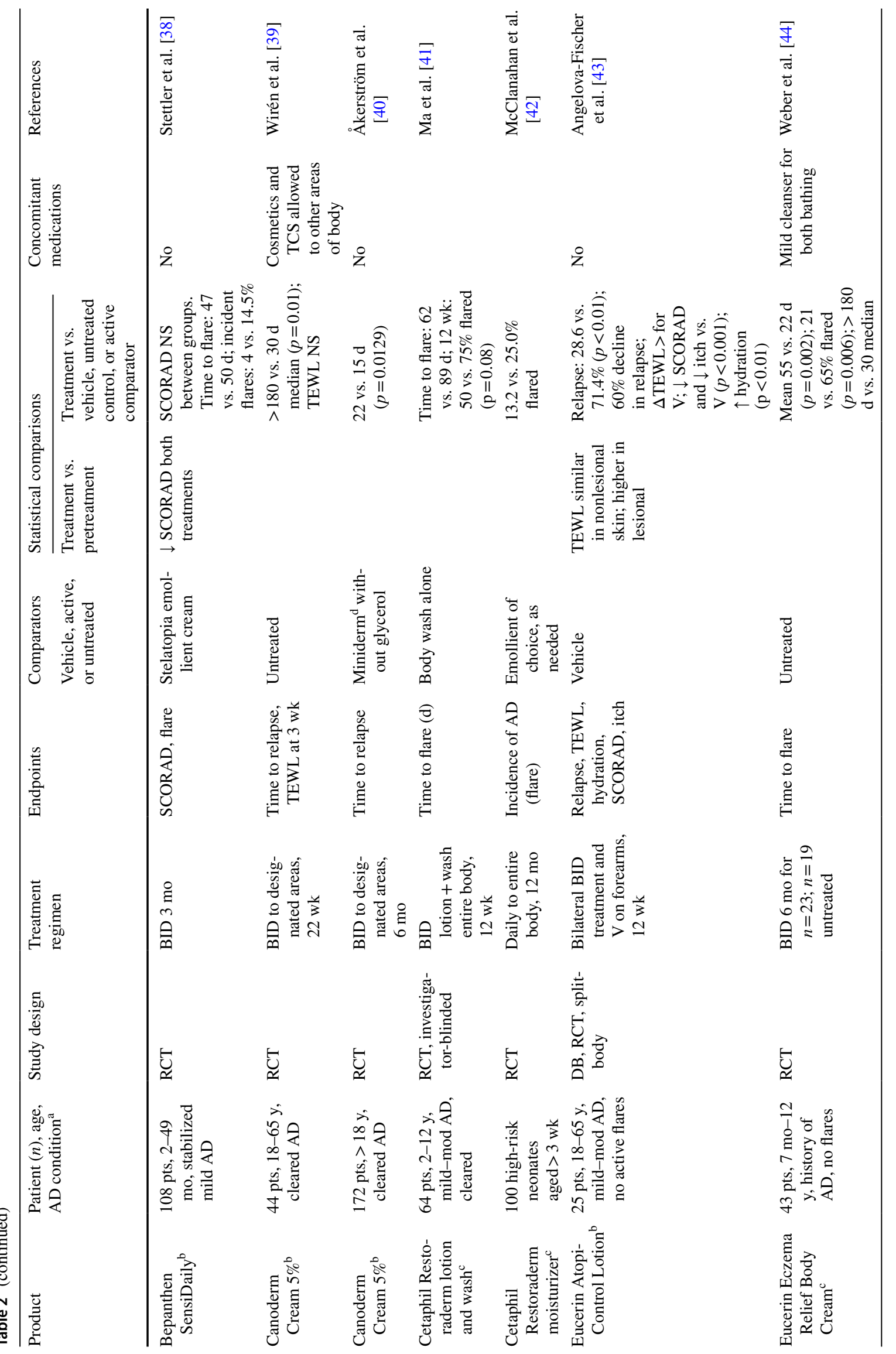




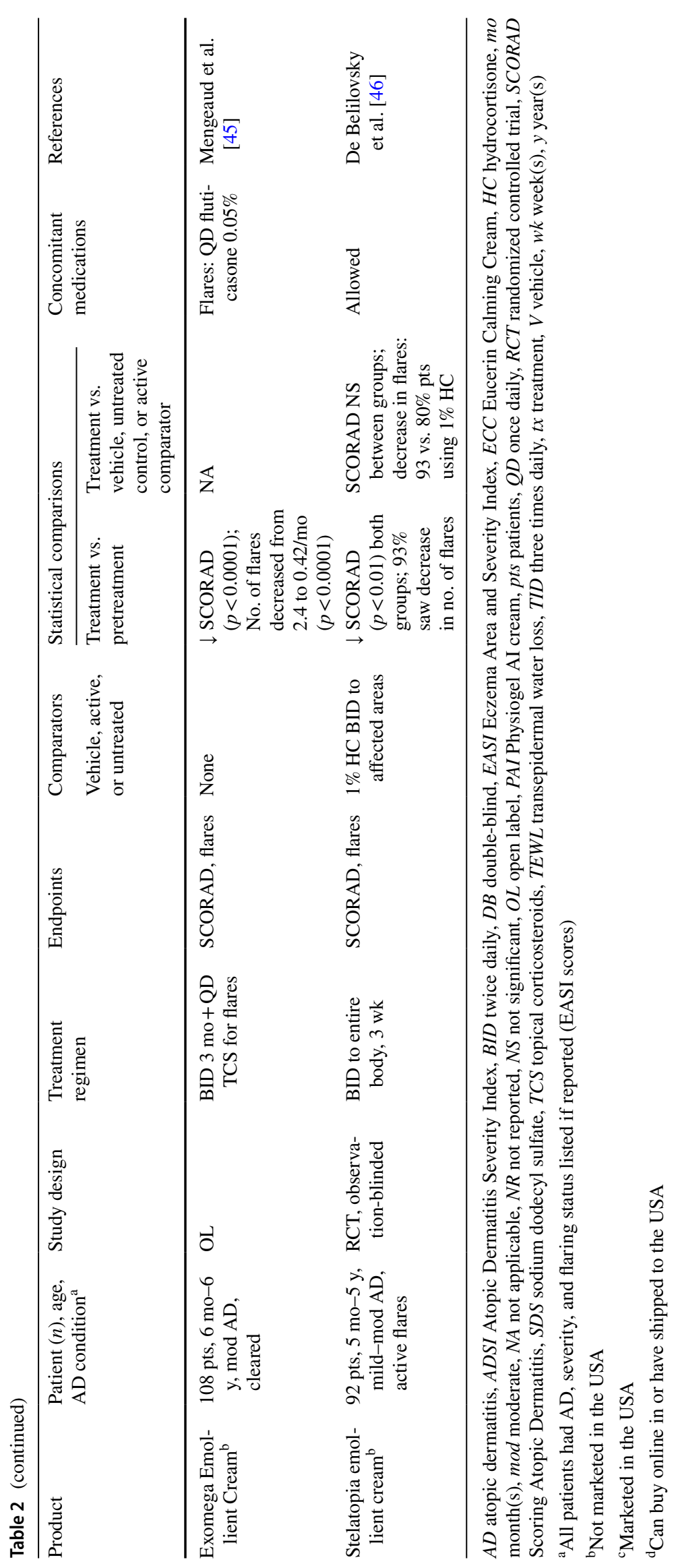


and support the skin barrier as well as hydration but also include ingredients that reduce inflammation or restore lipids, depending on the skin pathology being treated. Further, a true therapeutic moisturizer should be clinically evaluated and demonstrate efficacy for the respective conditions they are intended to treat [48].

Therapeutic moisturizers are formulated with ingredients that address the symptoms or contributory factors that may exacerbate the severity of the disease or condition (e.g., itch, inflammation, barrier disruption, ceramide deficiency). The formulation should have the physical properties that provide adequate absorption of ingredients and a $\mathrm{pH}$ of 4-5 to re-establish the normal physiological $\mathrm{pH}$ of skin. An aesthetically elegant product can potentially improve compliance.

\subsection{Classifying Moisturizers}

Understanding where therapeutic moisturizers for AD fit in among the plethora of topical agents can be complicated. The FDA classifies topical products as cosmetics, over-thecounter (OTC) drugs, prescription drugs, or prescription medical devices (Table 3 ). Cosmetic products are limited by the FDA to only claim effects on the appearance of the skin (per the US Federal Food and Cosmetic Act of 1938). Drugs are agents that have a pharmacologic action; prescription drugs require extensive clinical testing and approval by the FDA before being introduced to the market. OTC drugs must comply with their relevant OTC drug monograph, a guidance of acceptable ingredients and concentrations, disease indications, claims, dosing, and labeling. In contrast to prescription drugs, products conforming to existing OTC drug monographs can be marketed without FDA approval.
In order for any US moisturizer to be able to make claims of symptom relief for eczema, the FDA has designated only two ingredients as "allowed actives": (1) under the FDA's OTC External Analgesic monograph, hydrocortisone can claim use for the temporary relief of itching and inflammation due to eczema and (2) under the FDA's OTC Skin Protectant monograph, colloidal oatmeal can claim to provide temporary skin protection and relief of minor skin irritations and itching due to eczema [51]. These effects have been previously established in the literature and thus approved by the FDA. If a product does not contain either hydrocortisone or colloidal oatmeal, nor comply with the regulations in the relevant OTC monographs, no claims can be made regarding eczema relief.

In the USA, AD therapeutic moisturizers are nonprescription and may be classified as either cosmetic formulations or OTC drug products; these products typically avoid ingredients that may exacerbate diseased skin, such as fragrances $[2,50]$.

Several prescription barrier creams (e.g., Atopiclair, EpiCeram) are indicated for AD. Categorized as class II medical devices, these require a premarket FDA 501(k) submission, whereby the device must demonstrate "substantial equivalence" to already approved medical devices. These products do not need to demonstrate safety and clinical efficacy through rigorous clinical trials mandated by the FDA new drug application process [3]. Studies of barrier creams have shown them to be safe and to reduce the incidence of flares [5, 52]; however, several comparative studies have shown no greater efficacy than achieved with nonprescription moisturizers [53, 54]. Notably, many of the ingredients included in barrier creams when first developed (e.g., ceramides, NMFs) are now included in

Table 3 US FDA categorization of topical products used in atopic dermatitis

\begin{tabular}{|c|c|c|c|}
\hline \multirow{2}{*}{$\begin{array}{l}\text { Cosmetics (appearance or cleans- } \\
\text { ing): available without prescription }\end{array}$} & \multicolumn{2}{|c|}{ Drugs (agents with pharmacologic action) } & \multirow{2}{*}{$\begin{array}{l}\text { Medical devices (physically medi- } \\
\text { ated effects): requires prescription }\end{array}$} \\
\hline & OTC nonprescription drugs & Prescription drugs & \\
\hline FDA regulated, not FDA approved & FDA regulated, not FDA approved & $\begin{array}{l}\text { FDA approval requires NDA with } \\
\text { demonstration of safety and } \\
\text { efficacy required }\end{array}$ & $\begin{array}{l}\text { Premarket } 501(\mathrm{k}) \text { submission } \\
\text { requires demonstration of } \\
\text { substantial equivalence to an } \\
\text { existing barrier cream (limited } \\
\text { clinical efficacy testing part of } \\
\text { device application) }\end{array}$ \\
\hline $\begin{array}{l}\text { Limited to claim only effects on } \\
\text { the appearance of the skin }\end{array}$ & $\begin{array}{l}\text { Comply with FDA OTC drug } \\
\text { monographs }\end{array}$ & & $\begin{array}{l}\text { Barrier cream products have } \\
\text { physically (not chemically) } \\
\text { mediated effects }\end{array}$ \\
\hline $\begin{array}{l}\text { No claims of effects on structure, } \\
\text { function, or disease treatment } \\
\text { allowed }\end{array}$ & $\begin{array}{l}\text { For eczema, only products } \\
\text { containing } 0.007-2 \% \text { colloidal } \\
\text { oatmeal (OTC skin protectant) or } \\
1 \% \text { HC (OTC external analgesic) } \\
\text { are allowed to make claims about } \\
\text { effects on eczema symptoms }\end{array}$ & & \\
\hline
\end{tabular}

$H C$ hydrocortisone, NDA new drug application, OTC over the counter 
nonprescription moisturizers formulated for the treatment of eczema [3]. Moreover, barrier creams are more expensive than nonprescription products $[3,53]$, and insurance coverage may be improbable.

\subsection{Therapeutic Moisturizers for the Treatment of AD}

For $\mathrm{AD}$, therapeutic moisturizers need to provide essential barrier care (Table 4). Several AD therapeutic moisturizers have demonstrated their ability to decrease TEWL and increase skin hydration (e.g., Cetaphil Restoraderm moisturizer and wash, Eucerin Eczema Body Cream, Eucerin Flare-Up Treatment) and reduce the number of flares (e.g., Canoderm Cream, Eucerin Eczema Relief Body Cream, Eucerin AtopiControl Lotion) (see Table 2).

Sometimes termed "emollient plus" [2], AD therapeutic moisturizers go beyond basic emollients to include ingredients that provide skin protection, essential lipids, and antipruritic, anti-inflammatory, and antioxidant properties to help counter the symptoms of AD (Table 5).

Colloidal oatmeal contains a mixture of various dermatologic active compounds that provide moisturizing, skin-protectant, anti-inflammatory, antioxidant, and antipruritic effects. The starches and $\beta$-D-glucans in oatmeal help to create an occlusive barrier that both moisturizes and relieves itch, whereas antioxidants such as avenanthramides, vitamin $\mathrm{E}$, and ferulic acid have demonstrated anti-inflammatory activity [51].

Ceramides are important barrier lipids in preventing TEWL. Moisturizers may address ceramide deficiencies in $\mathrm{AD}$ by adding them to the formulation, by adding ingredients that can upregulate de novo ceramide production (e.g., urea [62, 63], niacinamide [64]), or by changing the physiologic milieu to support and promote ceramide production (e.g., lactic acid $[62,65])$.

\section{Maximizing Outcomes for Patients with AD}

Healthcare providers can maximize patient outcomes by stressing the benefits of daily emollient therapy to their patients, particularly highlighting flare prevention. Evidence has consistently shown that daily application of a therapeutic

Table 4 The importance of essential skin barrier repair in atopic dermatitis

Strengthens the barrier that protects against environmental triggers (e.g., skin irritants, aeroallergens, dust mites, pet dander)

Decreases moisture loss that perpetuates damage and can provoke inflammatory processes

Promotes a healthy microbiome via induction of antimicrobial peptides

Maintains stratum corneum acidification, which protects against pathogens

Reduces recurrence of flares when used daily

Prevents onset of atopic dermatitis when applied early in life to at-risk children

Table 5 Key ingredients in nonprescription therapeutic moisturizers for atopic dermatitis

\begin{tabular}{|c|c|}
\hline Therapeutic properties & Examples of ingredients \\
\hline Skin protectant & Colloidal oatmeal $^{\mathrm{a}}[51]$ \\
\hline Antipruritic & $\begin{array}{l}\text { Hydrocortisone }{ }^{\mathrm{b}} \text {, menthol }{ }^{\mathrm{c}}, \text { pramoxine } \mathrm{HCl}^{\mathrm{c}} \text {, menthoxypropan- } \\
\text { ediol }[55,56] \text {, colloidal oatmeal }{ }^{\mathrm{a}}[51]\end{array}$ \\
\hline Anti-inflammatory & Licochalcone A [57], hydrocortisone $^{\mathrm{b}}$, colloidal oatmeal ${ }^{\mathrm{a}}$ [51] \\
\hline Antioxidant & Glycyrrhetinic acid [58], licochalcone A [57] \\
\hline Essential barrier lipids & $\begin{array}{l}\text { Ceramides [59], plant oils rich in linoleic acid [60], urea (to } \\
\text { upregulate ceramide production) }\end{array}$ \\
\hline NMF & Lactic acid, amino acids, PCA, urea [61] \\
\hline $\mathrm{pH}$ buffer & Acidic buffers optimizing pH between 4 and 5 (e.g., citric acid) \\
\hline
\end{tabular}

$N M F$ natural moisturizing factor, $O T C$ over the counter, $P C A$ pyrrolidone carboxylic acid

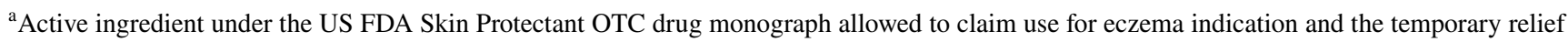
of its symptoms

${ }^{\mathrm{b}}$ Active ingredient under the US FDA External Analgesic OTC drug monograph, allowed to claim use for the temporary relief of itching and inflammation due to eczema

${ }^{\mathrm{c}}$ Active ingredient under the US FDA External Analgesic OTC drug monograph, allowed to claim use for the immediate relief of itching due to minor skin irritations, inflammation, and rashes due to eczema 
moisturizer improves the skin barrier and reduces the number and frequency of flares. These outcomes can result in greater quality of life and potential cost benefits by reducing the number of lost days at work [66]. For neonates, those at high risk of developing AD can delay or even avoid AD by proactive treatment with a therapeutic moisturizer (primary prevention) [37].

Recommending clinically proven therapeutic moisturizers to patients is key to a successful therapeutic outcome. Instructions should stress that moisturizers should be applied liberally and daily-ideally twice. Recommendations should be based on formula composition and the strength of clinical data supporting the formulation [48]. Clinical demonstrations should include both objective measures of skin hydration and TEWL and validated clinical scales to assess symptom improvement. Product selection should also consider patients' experience and preference $[67,68]$, as therapeutic efficacy can be provided in aesthetically pleasing, lighter formulations that can improve compliance.

Topical corticosteroids are generally recommended as the next step in the treatment of $\mathrm{AD}$, particularly for the targeted treatment of flares. Topical steroid formulations may include penetration enhancers designed to enhance the delivery of active steroid to its target, which may weaken the barrier. Consequently, maintaining daily moisturization is important when topical steroids are added to the treatment regimen [50].

\section{Limitations}

This review does not attempt to assess the quality of the studies reviewed (extensively evaluated by van Zuuren et al. [15]) but rather presents a practical guide for the clinician of therapeutic moisturizers and the data and studies that support their use.

Minimal clinically important differences (MCIDs [69]) were not addressed in any of the cited publications or this review because of a lack of information on both thresholds for objective biophysical measures (TEWL and corneometry) and MCID evaluations for nonprescription interventions for patients with mild to moderate conditions. Instead, we took a positive statistical difference in TEWL, corneometry, and reduction of flare incidence as evidence of the product being beneficial to the patient.

Furthermore, we focused on the effects of the products on clinical and biophysical skin measures. It is beyond the scope of this review to classify the products as being occlusive, humectant-enriched, or therapeutic, as many of them may span several classes.

\section{Conclusions}

Therapeutic moisturizers should be used daily as the bedrock of $\mathrm{AD}$ management, underlying all additional treatments. Evidence has shown that, in many cases, reinforcing a back-to-basics approach with daily moisturization can be sufficient for the treatment of mild AD, strengthening the skin barrier and reducing the symptoms and outbreaks of AD. This review identified several proven and available consumer products that have been clinically tested using objective measures. Understanding what makes a moisturizer therapeutic, and how they differ from cosmetic products and prescription barrier creams, will help healthcare providers make informed choices to optimize outcomes for their patients. Healthcare provider recommendations on the right choice of moisturizers for the patient should be based on clinical evidence and patients' preference and willingness to use. Twice-daily moisturization should be the mainstay of treatment for $\mathrm{AD}$.

Acknowledgements The authors thank Jodie Macoun, PhD, Cube Information Ltd, for editorial assistance in the preparation of this manuscript, funded by Beiersdorf Inc.

Author Contributions AAH: Conception and validation of the project, drafting of initial manuscript, critical review, approval of the final manuscript. TMW: Conception of the project, drafting of initial manuscript, critical review and revision of the manuscript, approval of the final manuscript. FR: Contribution of data collection and data analysis, critical review and revision of the manuscript, approval of the final manuscript. NHN: Conception and validation of the project, critical review, approval of the final manuscript.

\section{Compliance with Ethical Standards}

Funding A.A. Hebert and N.H. Nicol received compensation from Beiersdorf Inc. for time spent preparing this manuscript. Beiersdorf Inc. funded editorial assistance by Jodie Macoun, $\mathrm{PhD}$, Cube Information Ltd, as well as Open Access of this article.

Conflicts of interest In the previous 12 months, Adelaide A. Hebert has received honoraria from Beiersdorf, Biofrontera, Cassiopea, Dermira, Dermavant, Ferrer, Galderma, La Roche-Posay, Novartis, Ortho, ReLife, and Sun and research grants from Cutanea, Brickell, Cassiopea, Dermira, GSK, Leo, Mayne, Novan, Pfizer, Promius, Sienna, and SymBio. In the previous 12 months, Noreen Heer Nicol has served as an advisory board member for Eli Lilly \& Co. Frank Rippke and Teresa Weber are employees of Beiersdorf.

Open Access This article is licensed under a Creative Commons Attribution-NonCommercial 4.0 International License, which permits any non-commercial use, sharing, adaptation, distribution and reproduction in any medium or format, as long as you give appropriate credit to the original author(s) and the source, provide a link to the Creative Commons licence, and indicate if changes were made. The images or other third party material in this article are included in the article's Creative Commons licence, unless indicated otherwise in a credit line to the material. If material is not included in the article's Creative Commons licence and your intended use is not permitted by statutory 
regulation or exceeds the permitted use, you will need to obtain permission directly from the copyright holder. To view a copy of this licence, visit http://creativecommons.org/licenses/by-nc/4.0/.

\section{References}

1. National Eczema Association. Atopic Dermatitis: What is atopic dermatitis? https://nationaleczema.org/eczema/types-of-eczema/ atopic-dermatitis/. Accessed 19 Aug 2019.

2. Wollenberg A, Barbarot S, Bieber T, Christen-Zaech S, Deleuran M, Fink-Wagner A, et al. Consensus-based European guidelines for treatment of atopic eczema (atopic dermatitis) in adults and children: part I. J Eur Acad Dermatol Venereol. 2018;32(5):657-82.

3. Eichenfield LF, Tom WL, Berger TG, Krol A, Paller AS, Schwarzenberger K, et al. Guidelines of care for the management of atopic dermatitis: part 2. Management and treatment of atopic dermatitis with topical therapies. J Am Acad Dermatol. 2014;71(1):116-32.

4. LePoidevin LM, Lee DE, Shi VY. A comparison of international management guidelines for atopic dermatitis. Pediatr Dermatol. 2019;36:36-65.

5. Boguniewicz M, Fonacier L, Guttman-Yassky E, Ong PY, Silverberg J, Farrar JR. Atopic dermatitis yardstick: Practical recommendations for an evolving therapeutic landscape. Ann Allergy Asthma Immunol. 2018;120:10-22.

6. Mack Correa MC, Nebus J. Management of patients with atopic dermatitis: the role of emollient therapy. Dermatol Res Pract. 2012;2012:836931.

7. Lindh JD, Bradley M. Clinical effectiveness of moisturizers in atopic dermatitis and related disorders: A systematic review. Am J Clin Derm. 2015;16(5):341-59.

8. Sirikudta W, Kulthanan K, Varothai S, Nuchkull P. Moisturizers for patients with atopic dermatitis: an overview. J Allergy Ther. 2013;4(4):1-7.

9. Micali G, Paternò V, Cannarella R, Dinotta F, Lacarrubba F. Evidence-based treatment of atopic dermatitis with topical moisturizers. Giornale It Dermatol Venereol. 2018;153(3):396-402.

10. Brunner PM, Emerson RO, Tipton C, Garcet S, Khattri S, Coats I, et al. Nonlesional atopic dermatitis skin shares similar T-cell clones with lesional tissues. Allergy. 2017;72(12):2017-25.

11. Unger B, Garcet S, Gonzalez J, Dhingra N, da Rosa CJ, Shemer $\mathrm{A}$, et al. An integrated model of atopic dermatitis biomarkers highlights the systemic nature of the disease. J Invest Dermatol. 2017;137:603-13.

12. Lloyd-Lavery A, Solman L, Grindlay DJC, Rogers NK, Thomas KS, Harman KE. What's new in atopic eczema? An analysis of systematic reviews published in 2016. Part 2: epidemiology, aetiology and risk factors. Clin Exp Dermatol. 2016;2019(44):363-9.

13. Pavel AB, Zhou L, Diaz A, Ungar B, Dan J, He H, et al. The proteomic skin profile of moderate-to-severe atopic dermatitis patients shows an inflammatory signature. J Am Acad Dermatol. 2020;82(3):690-9.

14. Biagini Myers JM, Sherenian MG, Kyzy AB, Alarcon R, An A, Flege Z, Morgan D, Gonzalez T, Stevens ML, He H, Kroner JW, Spagna D, Grashel B, Martin LJ, Herr AB, Hershey GKK. Events in Normal Skin Promote Early-life Atopic Dermatitis-the MPAACH Cohort. J Allergy Clin Immunol Pract. 2020;S2213-2198(20):30354-8.

15. van Zuuren EJ, Fedorowicz Z, Christensen R, Lavrijsen A, Arents BWM. Emollients and moisturisers for eczema. Cochrane Database Syst Rev. 2017;2:CD012119.
16. Breternitz M, Kowatzki D, Langenauer M, Elsner P, Fluhr JW. Placebo-controlled, double-blind, randomized, prospective study of a glycerol-based emollient on eczematous skin in atopic dermatitis: biophysical and clinical evaluation. Skin Pharmacol Physiol. 2008;21:39-45.

17. Na JI, Hwang JS, Park HJ, Kim DH, Park WS, Youn SW, et al. A new moisturizer containing physiologic lipid granules alleviates atopic dermatitis. J Dermatolog Treat. 2010;21(1):23-7.

18. Bianchi P, Theunis J, Casas C, Villeneuve C, Patrizi A, Phulpin $\mathrm{C}$, et al. Effects of a new emollient-based treatment on skin microflora balance and barrier function in children with mild atopic dermatitis. Pediatr Dermatol. 2016;33(2):165-71.

19. Hon KL, Pong NH, Wang SS, Lee VW, Luk NM, Leung TF. Acceptability and efficacy of an emollient containing ceramideprecursor lipids and moisturizing factors for atopic dermatitis in pediatric patients. Drugs R D. 2013;13:37-42.

20. Simpson E, Dutronc Y. A new body moisturizer increases skin hydration and improves atopic dermatitis symptoms among children and adults. J Drugs Dermatol. 2011;10(7):744-9.

21. Simpson E, Trookman NS, Rizer RL, Preston N, Colón LE, Johnson LA, et al. Safety and tolerability of a body wash and moisturizer when applied to infants and toddlers with a history of atopic dermatitis: results from an open-label study. Pediatr Dermatol. 2012;29:590-7.

22. Hon KL, Wang SS, Lau Z, Lee HC, Lee KK, Leung TF, et al. Pseudoceramide for childhood eczema: does it work? Hong Kong Med J. 2011;17:132-6.

23. de Lucas R, García-Millán C, Pérez-Davó A, Moreno E, Redondo P. New cosmetic formulation for the treatment of mild to moderate infantile atopic dermatitis. Children (Basel). 2019. https://doi. org/10.3390/children6020017.

24. Schario M, Lünnemann L, Stroux A, Reisshauer A, Zuberbier T, Blume-Peytavi U, et al. Children with dry skin and atopic predisposition: daily use of emollients in a participant-blinded, randomized, prospective trial. Skin Pharmacol Physiol. 2014;27:208.

25. Weber TM, Herndon JH Jr, Ewer M, Stephens TJ, Flick I, Filbry A, et al. Efficacy and tolerability of steroid-free, over-the-counter treatment formulations in infants and children with atopic dermatitis. J Dermatol Nurses Assoc. 2015;7(1):17-24.

26. Wananukul S, Chatproedprai S, Chunharas A, Limpongsanuruk W, Singalavanija S, Nitiyarom R, et al. Randomized, double-blind, split-side, comparison study of moisturizer containing licochalcone $\mathrm{A}$ and $1 \%$ hydrocortisone in the treatment of childhood atopic dermatitis. J Med Assoc Thai. 2013;96(9):1135-42.

27. Simpson E, Böhling A, Bielfeldt S, Bosc C, Kerrouche N. Improvement of skin barrier function in atopic dermatitis patients with a new moisturizer containing a ceramide precursor. J Dermatolog Treat. 2013;24(2):122-5.

28. Seghers AC, Cai SC, Ho MS, Giam YC, Tan L, Grönhagen CM, et al. Evaluation of a pseudoceramide moisturizer in patients with mild-to-moderate atopic dermatitis. Dermatol Ther (Heidelb). 2014;4(1):83-92.

29. Koppes SA, Charles F, Lammers L, Frings-Dresen M, Kezic S, Rustemeyer T. Efficacy of a cream containing ceramides and magnesium in the treatment of mild to moderate atopic dermatitis: a randomized, double-blind, emollient- and hydrocortisonecontrolled trial. Acta Derm Venereol. 2016;96:948-53.

30. Weber TM, Babcock MJ, Herndon JH Jr, Schoelermann AM, Filbry AW, Scherdin U, et al. Steroid-free emollient formulations reduce symptoms of eczema and improve quality of life. J Drugs Dermatol. 2014;13(5):589-95.

31. Angelova-Fischer I, Neufang G, Jung K, Fischer TW, Zillikens D. A randomized, investigator-blinded efficacy assessment study of stand-alone emollient use in mild to moderately severe atopic dermatitis flares. J Eur Acad Dermatol Venereol. 2014;28(Suppl 3):9-15. 
32. Bomstein $\mathrm{Y}$, Rozenblat S. Treatment of atopic dermatitis with KAM-3008, a barrier-based, non-steroidal topical cream. J Dermatolog Treat. 2015;26(5):426-30.

33. Nasrollahi SA, Ayatollahi A, Yazdanparast T, Samadi A, Hosseini $\mathrm{H}$, Shamsipour M, et al. Comparison of linoleic acid-containing water-in-oil emulsion with urea-containing water-in-oil emulsion in the treatment of atopic dermatitis: a randomized clinical trial. Clin Cosmet Investig Dermatol. 2018;11:21-8.

34. Draelos ZD. A pilot study investigating the efficacy of botanical anti-inflammatory agents in an OTC eczema therapy. J Cosmet Dermatol. 2016;15:117-9.

35. Wakeman MP. An open-label forearm-controlled pilot study to assess the effect of a proprietary emollient formulation on objective parameters of skin function of eczema-prone individuals over 14 days. Clin Cosmet Investig Dermatol. 2017;10:275-83.

36. Gayraud F, Sayag M, Jourdan E. Efficacy and tolerance assessment of a new type of dermocosmetic in infants and children with moderate atopic dermatitis. J Cosmet Dermatol. 2015;14(2):107-12.

37. Simpson EL, Chalmers JR, Hanifin JM, Thomas KS, Cork MJ, McLean WH, et al. Emollient enhancement of the skin barrier from birth offers effective atopic dermatitis prevention. J Allergy Clin Immunol. 2014;134(4):818-23.

38. Stettler H, Kurka P, Kandzora J, Pavel V, Breuer M, MacuraBiegun A. A new topical panthenol-containing emollient for maintenance treatment of childhood atopic dermatitis: results from a multicenter prospective study. J Dermatolog Treat. 2017;28(8):774-9.

39. Wirén K, Nohlgård C, Nyberg F, Holm L, Svensson M, Johannesson A, et al. Treatment with a barrier-strengthening moisturizing cream delays relapse of atopic dermatitis: a prospective and randomized controlled clinical trial. J Eur Acad Dermatol Venereol. 2009;23(11):1267-72.

40. Åkerström U, Reitamo S, Langeland T, Berg M, Rustad L, Korhonen $\mathrm{L}$, et al. Comparison of moisturizing creams for the prevention of atopic dermatitis relapse: a randomized doubleblind controlled multicentre clinical trial. Acta Derm Venereol. 2015;95(5):587-92.

41. Ma L, Li P, Tang J, Guo Y, Guo Y, Shen C, Chang J, et al. Prolonging time to flare in pediatric atopic dermatitis: a randomized, investigator-blinded, controlled, multicenter clinical study of a ceramide-containing moisturizer. Adv Ther. 2017;34(12):2601-11.

42. McClanahan D, Wong A, Kezic S, Samrao A, Hajar T, Hill E, et al. A randomized controlled trial of an emollient with ceramide and filaggrin-associated amino acids for the primary prevention of atopic dermatitis in high-risk infants. J Eur Acad Dermatol Venereol. 2019;33(11):2087-94.

43. Angelova-Fischer I, Rippke F, Richter D, Filbry A, Arrowitz C, Weber T, et al. Stand-alone emollient treatment reduces flares after discontinuation of topical steroid treatment in atopic dermatitis: a double-blind, randomized, vehicle-controlled, left-right comparison study. Acta Derm Venereol. 2018;98(5):517-23.

44. Weber TM, Samarin F, Babcock MJ, Filbry A, Rippke F, et al. Steroid-free over-the-counter eczema skin care formulations reduce risk of flare, prolong time to flare, and reduce eczema symptoms in pediatric subjects with atopic dermatitis. J Drugs Dermatol. 2015;14(5):478-85.

45. Mengeaud V, Phulpin C, Bacquey A, Boralevi F, Schmitt AM, Taieb A. An innovative oat-based sterile emollient cream in the maintenance therapy of childhood atopic dermatitis. Pediatr Dermatol. 2015;32(2):208-15.

46. De Belilovsky C, Roo-Rodriguez E, Baudouin C, Menu F, Chadoutaud B, Msika P. Natural peroxisome proliferator-activated receptor-alpha agonist cream demonstrates similar therapeutic response to topical steroids in atopic dermatitis. J Dermatolog Treat. 2011;22(6):359-65.
47. Schachner LA, Hebert AA, Andriessen A, et al. A global review on the risk factors and management of early atopic dermatitis in children ages 0 to 2 years old. J Drugs Dermatol. 2019;18(10):1020-7.

48. Elias PM, Wakefield JS, Man MQ. Moisturizers versus current and next-generation barrier repair therapy for the management of atopic dermatitis. Skin Pharmacol Physiol. 2019;32:1-7.

49. Bhanot A, Huntley A, Ridd MJ. Adverse events from emollient use in eczema: a restricted review of published data. Dermatol Ther (Heidelb). 2019;9(2):193-208.

50. Draelos ZD. Modern moisturizer myths, misconceptions, and truths. Cutis. 2013;91(6):308-14.

51. Fowler JF, Nebus J, Wallo W, Eichenfield LF. Colloidal oatmeal formulations as adjunct treatments in atopic dermatitis. J Drugs Dermatol. 2012;11:804-7.

52. Abramovits W, Boguniewicz M, Adult Atopiclair Study Group. A multicenter, randomized, vehicle-controlled clinical study to examine the efficacy and safety of MAS063DP (Atopiclair) in the management of mild to moderate atopic dermatitis in adults. J Drugs Dermatol. 2006;5(3):236-44.

53. Miller DW, Koch SB, Yentzer BA, Clark AR, O’Neill JR, Fountain $\mathrm{J}$, et al. An over-the-counter moisturizer is as clinically effective as, and more cost-effective than, prescription barrier creams in the treatment of children with mild-to-moderate atopic dermatitis: a randomized, controlled trial. J Drugs Dermatol. 2011;10:531-7.

54. Draelos ZD. An evaluation of prescription device moisturizers. J Cosmet Dermatol. 2009;8:40-3.

55. Misery L, Santerre A, Batardière A, Hornez N, Nedelec AS, Le Caër F, et al. Real-life study of anti-itching effects of a cream containing menthoxypropanediol, a TRPM8 agonist, in atopic dermatitis patients. J Eur Acad Dermatol Venereol. 2019;33(2):e67-9.

56. Ständer S, Augustin M, Roggenkamp D, Blome C, Heitkemper T, Worthmann AC, et al. Novel TRPM8 agonist cooling compound against chronic itch: results from a randomized, double-blind, controlled, pilot study in dry skin. J Eur Acad Dermatol Venereol. 2017;31:1064-8.

57. Kolbe L, Immeyer J, Batzer J, Wensorra U, Dieck TK, Mundt $\mathrm{C}$, et al. Anti-inflammatory efficacy of licochalcone A: correlation of clinical potency and in vitro effects. Arch Dermatol Res. 2006;298(1):23-30.

58. Kowalska A, Kalinowska-Lis U. 18ß-Glycyrrhetinic acid: its core biological properties and dermatological applications. Int J Cosmet Sci. 2019;41(4):325-31.

59. Kahraman E, Kaykin M, Bektay HS, Güngör S. Recent advances on topical application of ceramides to restore barrier function of skin. Cosmetics. 2019;6:52.

60. Vaughn AR, Clark AK, Sivamani RK, Shi VY. Natural oils for skin-barrier repair: ancient compounds now backed by modern science. Am J Clin Dermatol. 2018;19(1):103-17.

61. Celleno L. Topical urea in skincare: a review. Dermatol Ther. 2018;31(6):e12690

62. Rawlings AV, Davies A, Carlomusto M, Pillai S, Zhang K, Kosturko R, et al. Effect of lactic acid isomers on keratinocyte ceramide synthesis, stratum corneum lipid levels and stratum corneum barrier function. Arch Dermatol Res. 1996;288(7):383-90.

63. Pigatto PD, Bigardi AS, Cannistraci C, Picardo M. $10 \%$ urea cream (Laceran) for atopic dermatitis: a clinical and laboratory evaluation. J Dermatol Treat. 1996;7:171-5.

64. Tanno O, Ota Y, Kitamura N, Katsube T, Inoue S. Nicotinamide increases biosynthesis of ceramides as well as other stratum corneum lipids to improve the epidermal permeability barrier. Br J Dermatol. 2000;143(3):524-31.

65. Rippke F, Schreiner V, Schwanitz HJ. The acidic milieu of the horny layer: new findings on the physiology and pathophysiology of skin pH. Am J Clin Dermatol. 2002;3(4):261-72. 
66. Zink AGS, Arents B, Fink-Wagner A, Seitz IA, Mensing U, Wettemann N, et al. Out-of-pocket costs for individuals with atopic eczema: a cross-sectional study in nine European countries. Acta Derm Venereol. 2019;99(3):263-7.

67. Hon KL, Wang SS, Pong NH, Leung TF. The ideal moisturizer: a survey of parental expectations and practice in childhood-onset eczema. J Dermatolog Treat. 2013;24(1):7-12.
68. Ridd MJ, Roberts A, Grindlay D, Williams HC. Which emollients are effective and acceptable for eczema in children? BMJ. 2019;367:15882.

69. Basra MK, Salek MS, Camilleri L, Sturkey R, Finlay AY. Determining the minimal clinically important difference and responsiveness of the Dermatology Life Quality Index (DLQI): further data. Dermatology. 2015;230(1):27-33. 